\title{
Do Paradigma ao Paradoxo Ético-Estético-Político: Por uma Radicalização da Psicologia Social
}

The Ethical-Aesthetic-Political Paradox: Towards a Radicalization of Social Psychology

Del Paradigma a la Paradoja Ético-Estética-Política: Por una Radicalización de la Psicología Social

\author{
Daniel Kveller
}

Daniel Rodrigues Fernandes

Diego Drescher de Castro

Renata Flores Trepte

Universidade Federal do Rio Grande do Sul (UFRGS), Porto Alegre, RS, Brasil

\section{Resumo}

"Como pode a psicologia social contribuir para pensar o presente?". Partindo dessa interrogação, este artigo objetiva questionar a obviedade por meio da qual enxergamos uma certa psicologia social, um certo tempo presente e uma certa relação entre ambos. Interessanos, sobretudo, problematizar a ideia de um paradigma ético-estético-político, o que realizamos em três movimentos complementares: questionamos a caracterização desse paradigma como uma evolução no campo da psicologia social, relacionamos essa caracterização a uma narrativa de progresso mais ampla sobre a política brasileira recente, e criticamos alguns dos seus pressupostos teóricos-epistemológicos a partir de um diálogo com estudos de gênero, de raça, pós-coloniais e descoloniais. Como conclusão, retornamos à pergunta inicial para sugerir que, antes de examinar o presente, a psicologia social deve se valer deste presente para radicalizar os seus pressupostos, rompendo com a ideia de um paradigma ético-estético-político em favor de um paradoxo ético-estético-político.

Palavras-chave: Psicologia Social; Paradigma ético-estético-político; Epistemologia; Temporalidade; Universidade.

\begin{abstract}
"How can Social Psychology help us think about the present?". Taking this interrogation as a starting point, we question what seems to be an "obvious" way to understand a certain social psychology, a certain present, and a certain relationship between these two terms. Our main goal is to problematize the so-called ethical-aesthetic-political paradigm, and we proceed through three complementary sections: we question how this paradigm is characterized as an evolution in the field of Social Psychology; we relate this characterization to a broader interpretation of Brazilian politics as a narrative of progress; and we criticize some of its
\end{abstract}


theoretical-epistemological assumptions while dialoguing with gender studies, critical race studies, postcolonial and decolonial studies. Finally, we return to our starting point to suggest that, before examining the present, Social Psychology should use it to radicalize its own epistemological and political assumptions, moving away from the idea of an ethical-aestheticpolitical paradigm towards an ethical-aesthetic-political paradox..

Key-words: Social psychology; ethical-aesthetic-political paradigm; Epistemology; Temporality; University.

\section{Resumen}

"¿Cómo puede contribuir la psicología social a pensar el presente?" A partir de esta interrogación, cuestionamos la obviedad a través de la cual se percibe una determinada psicología social, un determinado tiempo presente y una determinada relación entre ambos. Nos interesa sobre todo problematizar la concepción de un paradigma ético-estético-político, y para ello caminamos por tres vías complementarias: cuestionamos la caracterización de ese paradigma como una evolución en el campo de la psicología social; relacionamos esa caracterización a una narrativa de progreso más amplia sobre la política brasileña reciente; y criticamos algunos de sus presupuestos teórico-epistemológicos, dialogando con los estudios de género, raza, poscoloniales y decoloniales. Como conclusión, volvemos a la pregunta inicial para sugerir que, antes de examinar el presente, la psicología social debería utilizar ese mismo presente con vías a radicalizar sus directrices políticas y epistemológicas, rompiendo con la idea de un paradigma ético-estético-político en favor de una paradoja ético-estéticopolítica.

Palabras clave: Psicología social; Paradigma ético-estético-político; Epistemología; Temporalidad; Universidad.

\section{Introdução}

Como pode a psicologia social contribuir para pensar o presente? Essa foi a pergunta sugerida como tema para um evento do Programa de Pós-Graduação em Psicologia Social e Institucional da Universidade Federal do Rio Grande do Sul, realizado em outubro de 2019, e que agora ganha forma escrita com a publicação deste dossiê. Talvez não por acaso, para refletir sobre possibilidades de respostas ao questionamento, formamos um grupo bastante particular. Nós, que aqui escrevemos, fizemos o percurso de graduação em psicologia nesta universidade, entre os anos de 2007 e 2014. Fizemos parte das primeiras turmas a experienciar um novo currículo e, portanto, a ter contato com a psicologia social desde os primeiros momentos do curso $^{1}$. Contando eventuais afastamentos e deslocamentos, pudemos acompanhar o trabalho do Departamento de Psicologia Social e Institucional desde as primeiras disciplinas da graduação até as aulas dos 
cursos de mestrado e doutorado, passando pela ênfase em Psicologia e Políticas Públicas, por atividades de extensão e pela iniciação científica. Passaram-se mais de 10 anos nesse processo, um tempo curto para a história da psicologia, mas suficiente para testemunhar grandes transformações no curso de graduação, nas universidades federais e no cenário político, a níveis tanto internacional quanto local.

Durante esse período, em campos de estágio, campos de residência e campos de trabalho, ouvimos repetidas vezes que profissionais egressos da UFRGS são facilmente identificáveis. É difícil reconhecer em nós mesmos nosso próprio sotaque, mas, quando nos deparamos com sonoridades e expressões distintas, a diferença nos aponta algo de nossa própria singularidade. Talvez nos identifiquem pelo discurso crítico, pela nossa insistência em assinalar os atravessamentos políticos, as contingências históricas e sociais de nossas práticas; ou, talvez, pelos nossos jargões, pelos dispositivos, pelos afetos, pelas resistências, expressões que são traços de um modo específico de pensar e fazer psicologia, um modo específico que aprendemos a identificar logo na disciplina de Psicologia Social I pelo nome de "paradigma ético-estético", ou, ainda, “paradigma ético-estético-político".

É claro, muito mudou desde então. Quando chegamos, o clima era de otimismo: investimentos, ampliações, transformações. Inclusão, democratização, valorização. Impulsionadas pela injeção de verbas $^{2}$, as universidades federais floresciam em projetos de extensão e bolsas para pesquisas, enquanto a implementação das ações afirmativas sustentava a percepção de que passos importantes eram dados em direção à diminuição da desigualdade social no país. Uma época de prosperidade que só se revelou para nós desta forma quando foi perdendo seus contornos, quando, por contraste, naquilo que parecia tão sólido, foi possível gradualmente enxergarmos uma fragilidade angustiante. De investimento de ponta, setor estratégico no desenvolvimento no país, passamos a viver entre cortes, contingenciamentos, tetos de gastos $^{3}$. A promessa de nossos saberes, tão exaltada e confiada outrora, parecia já não brilhar tanto a novos olhos. No que pareceu um breve momento, nossa ciência, antes motor do progresso, se tornou perigosa, profanação a ser corrigida ou, simplesmente, balbúrdia ${ }^{4}$.

As transformações foram também de outra ordem. Hoje, quando visitamos as 
salas de aula da graduação, agora como parte de estágios de docência, entramos em contato com novas discussões, somos interpelados desde outros lugares, ouvimos novos jargões, sotaques, sonoridades, vemos novas cores. Assuntos que antes apareciam com certa timidez, como gênero e sexualidade, hoje são destacados; cada vez mais em pauta, as temáticas étnicoracial, pós-colonial e descolonial $^{5}$, interseccional, raríssimas vezes eram comentadas dez anos atrás. Antes vistas por nosso campo teórico e conceitual com certo receio, as chamadas questões identitárias hoje ganham mais espaço. E certamente o são depois de muita insistência por parte de quem depende dessa discussão para existir no ambiente acadêmico ${ }^{6}$.

Talvez tenhamos os quatro nos reunido, então, pois reagimos de maneira parecida à pergunta sobre como a psicologia social pode contribuir para intervir no presente. Qual psicologia social? Que presente? E, principalmente, qual é exatamente a urgência que torna o "presente" uma questão para a "psicologia social" neste momento?

A premissa deste artigo é a aposta em uma psicologia social que não ressinta o presente como anômalo de um passado em progresso. Nesse sentido, entendemos Rev. Polis e Psique, 2021; 11(1): 123 - 142 que interrogar o que a psicologia social tem a dizer sobre o presente passa necessariamente por um posicionamento crítico em relação à própria questão. Propomos essa crítica por meio de uma reflexão sobre a confiança no progresso implícita na formulação de um "paradigma ético-estético", confiança essa que vai de encontro às próprias bases teóricas e epistemológicas desse paradigma. Especificamente, interessa-nos indicar como os estudos feministas, antirracistas, pós-coloniais e descoloniais podem ajudar a entender melhor esse paradoxo, não necessariamente com o objetivo de resolvê-lo, mas de levá-lo a sua radicalidade, e, portanto, à radicalidade da própria psicologia social.

\section{Uma questão de paradigmas}

Conhecemos o paradigma éticoestético-político logo no primeiro semestre de graduação, na disciplina de Psicologia Social I. Temos vívidas recordações da aula em questão e dos slides de power point utilizados. Eles iniciavam pelo paradigma positivista, que era ilustrado com um bonequinho que mirava um globo terrestre. Nos explicaram que esse paradigma, nascido na modernidade clássica com René Descartes, se 
consolidou no norte global ao longo do século XX, tomando a realidade como passível de apreensão, compreensão e representação de forma estática, por um observador/pesquisador exterior e neutro.

$\mathrm{O}$ slide seguinte apresentava um segundo paradigma, o paradigma materialista dialético, ilustrado pelo mesmo bonequinho e pelo mesmo globo terrestre. Havia uma seta que saía do bonequinho em direção ao globo e outra que retornava, do globo ao bonequinho. Nos explicaram que este paradigma havia surgido num esforço crítico em relação ao primeiro paradigma, o positivista, tensionando a compreensão dos processos sociais ao longo da história, e que ganhara força e desdobramento principalmente na América Latina. Vivíamos aqui, afinal, um contexto completamente distinto do norte global. Estávamos sob ditadura e era necessário destacar a dimensão política do conhecimento, sobretudo o modo como a psicologia poderia intervir sobre a realidade e como a própria realidade transformava a psicologia. Como disse Marx, nas teses sobre Feuerbach, "Os filósofos têm apenas interpretado o mundo de maneiras diferentes; a questão, porém, é transformá-1o" $"$.

O último slide, por fim, apresentaria o paradigma ético-estético, que era ilustrado também pelo bonequinho e pelo globo terrestre. Dessa vez, no entanto, essas duas imagens estavam sobrepostas, e foi-nos explicado que esse paradigma entendia que sujeito e mundo são indissociáveis. Tal como no paradigma anterior, o materialista-dialético, havia um destaque para a intervenção e para a transformação, mas aqui as coisas já estavam tão embaralhadas que não seria possível entendermos as personagens como entes distintos e sua ação no mundo como um processo bem delimitado no tempo e no espaço.

De acordo com Silva (2008, p. 44), no paradigma ético-estético as "estratégias de produção do conhecimento estarão voltadas para identificar as formas de captura da subjetividade pelos modos de subjetivação dominantes". Esse exercício se dá por meio de uma crítica permanente aos modos de valorização intrínsecos à lógica capitalista, a qual tende a produzir uma equivalência generalizada entre todas as coisas. Diferente de um paradigma positivista - que procede por uma metáfora arborescente em que o saber ganha uma estrutura hierarquizada, com origem definida em suas raízes, um robusto tronco de argumentos principais, espraiando-se de forma a revelar uma grande árvore do conhecimento -, o paradigma ético-estético 
convoca o conceito de Rizoma, proposto por Gilles Deleuze e Félix Guattari, dando imagem à ideia de que não existe origem, ou pressuposto último que sustenta o conhecimento, do qual tudo se ramifica. Silva destaca que

o rizoma ramifica-se em múltiplas direções e cresce de acordo com as conexões que se realizam, passando, portanto, a ideia de aliança e não a de filiação. Trata-se de uma rede não hierárquica, que não tem começo nem fim; o rizoma encontra-se sempre no meio, entre as coisas, produzindo sempre novos e múltiplos agenciamentos (Silva, 2008, p. 44).

A ética que nomeia este paradigma não deve ser confundida com a Moral, mas relacionada a modos contingentes e situados de ser e habitar o mundo. A estética, por sua vez, não deve ser colada à busca por uma referência transcendental do Belo ou a algum tipo de comércio ou mercadoria, mas sim entendida como um articulador. Estética implica a dimensão produtiva de si e dos mundos. A arte é tomada aqui para situar a resistência às formas de assujeitamento como criação permanente de novos modos de existência.
Esta dimensão ético-estética aproxima-se bastante intimamente da perspectiva que Michel Foucault traça sobretudo no terço final de sua obra, "aos valores que constituem nossa ação no mundo (...) e à recriação permanente de nossa própria existência como uma obra de arte" (Silva, 2008, p. 45).

Se lidamos aqui com a ética enquanto experiência relacional de modos sempre contingentes e tateantes de situarse no mundo e dos valores que aí se criam (ou questionam), e com a estética enquanto dimensão produtiva que dá existência a formas de viver, podemos dizer que estamos fortemente implicados também no campo da responsabilização política. A concepção aqui invocada de psicologia social entende que as tecnologias de subjetivação e os modos de operar presença no campo social inventam, afirmam e questionam diferentes projetos de mundo, o que coloca a questão (e tarefa) de ocuparmo-nos dessa recriação das formas de operar a existência e suas possibilidades. Reconhecer, tal como Foucault aponta (não com um otimismo inocente, mas com um apelo a certa responsabilidade e ação) que somos mais livres do que cremos (Foucault, 2014).

Do paradigma positivista ao paradigma ético-estético-político: assim 
nos foi apresentada uma linha evolutiva que começava na pressuposição ingênua de uma neutralidade científica, passando pelo despertar da consciência política com o materialismo-dialético, até finalmente desembocar na sofisticação teórica e política de autores como Gilles Deleuze, Félix Guattari e Michel Foucault. Fomos encorajados a adotar este último paradigma como guia para nosso trabalho como psicólogos e psicólogas, presumindo que havia superado limitações dos paradigmas anteriores - principalmente a despolitização do positivismo e a rigidez do marxismo -, bem como o problema das identidades. Assumimos para nós a crítica que esses autores fizeram à filosofia iluminista como projeto de modernidade e razão emancipadora: a crítica ao racionalismo, à dialética hegeliana e seu idealismo, e à concepção de mundo fundada em divisões binárias tais como indivíduo/ sociedade, sujeito/objeto e natureza/cultura.

É importante notar que a filosofia da diferença e o pós-estruturalismo francês migram para o "Sul global" em um contexto de autoritarismo e violência por parte das ditaduras latino-americanas da segunda metade do século XX e são assimilados em um esforço antropofágico para a constituição de uma psicologia social que dialogasse com as epistemologias do "terceiro mundo". Nesse processo, o estrangeiro aparece não como colonizador do pensamento, mas como um outro a ser devorado. Trata-se, nas palavras de Suely Rolnik, de "engolir o outro, sobretudo o outro admirado, de forma que partículas do universo desse outro se misturem às que já povoam a subjetividade do antropófago e, na invisível química dessa mistura, se produza uma verdadeira transmutação" (Rolnik, 2000, pp. 452453).

Apesar do empreendimento antropofágico e do próprio devir minoritário desta filosofia, tão poderosamente descritos por Suely Rolnik, não nos parece que tenhamos conseguido escapar, de todo, da armadilha colonial que cerca a produção de conhecimento. E se caracterizamos a lógica colonialista como uma armadilha é porque entendemos que nós mesmos, nesses anos todos dedicados ao estudo e ao trabalho com psicologia, apenas recentemente começamos a enxergar com um pouco mais de nitidez os perigos de havermos importado o pensamento de três filósofos europeus, os perigos de termos enxergado na sofisiticação da filosofia pós-identitária francesa soluções para problemas que ainda precisavam ser entendidos como 
problemas no Brasil. O contato com os atuais estudantes de graduação, que tanto falam sobre identidades, classes e representações, nos faz olhar para trás e estranhar aqueles slides, aqueles bonequinhos e aqueles globos terrestres, e nos faz duvidar da linha de evolução que se desenhava entre eles. Nesse ciclo de tantos estranhamentos, nos surpreendemos sobretudo por termos confiado tanto nesses três filósofos - Michel Foucault, Gilles Deleuze e Félix Guattari -, logo eles que falavam tanto da importância de desconfiar dos mestres.

A psicologia social no Brasil que se localiza no paradigma ético-estéticopolítico convive com esta ambiguidade epistemológica, com o risco de ter firmado filiação e colocado em posição de mestria pensadores cujas filosofias recusaram e problematizaram justamente esses lugares e relações de poder. É desde dentro desse paradoxo que vivenciamos a psicologia social, e é o assombro com o tempo presente que o torna evidente para nós.

\section{Assombro e a crítica ao progresso}

Para além das bases filosóficas, nossa psicologia social tem uma história recente bastante material: ela ganha especial relevância no campo de produção científica nacional durante o período chamado progressista, em que certo desenvolvimentismo era afirmado como política econômica. Por relevância, aqui, nos referimos não só a aportes financeiros, mas a influência no campo acadêmico e na formulação de políticas estratégicas. Nesse processo, em muito distanciou-se o pensamento dos movimentos sociais, os quais passaram em alguns casos a fazer parte do próprio funcionamento do Estado, para acompanhar com maior ênfase a formulação e implementação de políticas públicas, na esperança de qualificá-las. Nosso campo é tomado então por um desejo de projetos - críticos, mas propositores a partir de um lugar de evidência e até centralidade; nos tornamos crentes e entusiastas da direção que esse momento histórico apontava. Então, chegamos ao presente, e o cenário que se apresenta causa espanto.

A pergunta que embasa esse escrito - "como pode a psicologia social contribuir para pensar o presente?" evoca também um assombro. Como podemos, depois de todos esses anos, depois de havermos "progredido" tanto em tão pouco tempo, sermos atemorizados por uma ameaça que já havíamos dado como morta? Que ferramentas teremos para enfrentá-la quando a sua própria presença 
atesta a insuficiência de nossos meios? Mais do que no assombro, vivemos agora assombrados por fantasmas, rodeados por espectros que circulam e nos indicam que o passado que julgávamos haver superado pode ser ainda, de alguma forma, assustadoramente presente.

O tema do assombro é trabalhado por Walter Benjamin (1987) em suas teses Sobre o conceito de história, um conjunto de fragmentos herméticos, repleto de aforismas enigmáticos e imagens provocativas, publicado postumamente. A crítica central dessas teses dirige-se ao historicismo, às suas pretensões positivistas e universalizantes, e, especialmente, à sua íntima ligação com a ideia de progresso. Para o filósofo, o progresso nada mais seria do que uma ideologia que recobre matanças, que anestesia as pessoas em relação à quantidade de mortos, guerras e batalhas que se trava em seu nome e que, assim, produz esquecimento. A ascensão do nazifascismo não era vista por Benjamin como um "retrocesso" ou um ponto fora da curva do progresso, como foi interpretado em seu tempo pelos movimentos de esquerda, mas, justamente pelo contrário, como um produto direto da modernidade e de suas íntimas relações com a sociedade industrial capitalista. Aqueles que se assombravam com o momento político estariam cegos pela crença de que a barbárie social e política do fascismo era incompatível com o progresso técnico, científico e industrial: "O assombro com o fato de que os episódios que vivemos no século XX 'ainda' sejam possíveis, não é um assombro filosófico. Ele não gera nenhum conhecimento, a não ser o conhecimento de que a concepção de história da qual emana semelhante assombro é insustentável" (Benjamin, 1987, p. 226).

Vão-se já quase oitenta anos desde as teses Sobre o conceito de história, mas sua atualidade segue impressionante. Seguimos testemunhando catástrofes, ambientais e humanitárias, embora tenhamos desenvolvido as mais apuradas técnicas para evitá-las; seguimos apostando que o futuro ainda nos reserva algo melhor, somos o país do futuro, e até agora essa promessa tem apenas nos tornado surdos às demandas de passados não redimidos; após um relativamente longo período de governo progressista (e talvez essa nomenclatura já devesse nos deixar mais atentos), quando finalmente o trem parecia ter se acomodado nos trilhos, assistimos uma reação conservadora que ameaça pôr em xeque resultados de décadas de lutas. E tudo isso, é claro, 
segue deixando-nos profundamente assombrados.

Quando essa psicologia social percebe-se, também, assombrada com o presente, não estaria fazendo ver seu próprio tropeço epistemológico? Tal qual o assombro proposto por Benjamin em relação à quebra na linearidade do progresso, podemos pensar em um certo abalo no arcabouço epistemológico que sustenta a psicologia social, principalmente a partir de sua consolidação na América Latina? Um dissenso entre a filosofia que inspirou a formulação de uma psicologia social ético-estética-política e as experiências enquanto comunidade acadêmica e militância de esquerda?

Poderíamos dizer que as teses de Benjamin vão além de uma crítica ao materialismo-dialético, convocando um reposicionamento epistêmico a partir da reconfiguração da relação entre conhecimento e tempo. E, além disso, que Benjamin estabelece uma relação entre afeto e conhecimento. $\mathrm{O}$ saber que advém do assombro, para ele, é um saber inútil ou, melhor dizendo, é um saber que só é útil para interrogar o próprio assombro. $\mathrm{O}$ historiador verdadeiramente comprometido com o materialismo dialético deve recusar o assombro e se manter atento para pinçar no momento presente o lampejo das centelhas do passado.

Esse lampejo do passado que ainda crepita é possibilidade de operar sobre o presente em sentido oposto à continuidade da linha do progresso. O passado, para Benjamin, não é algo que passou e segue preservado no transcorrer da história, mas algo inseguro que é disputado no agora. Sua quinta tese aponta que o presente preserva tão somente o passado que o sustenta, e que é tarefa do novo historiador tomar-se da convocação dessa centelha (cujo brilho provém da aeração que perigo e possibilidade lhe dão) e fazer dela uma arma com a qual produzir divergência no curso da história.

Vivemos um momento de pessimismo não organizado $^{8}$, onde proliferam leituras do que acontece, mas não se vislumbram saídas ou estratégias de ação. Nosso presente (e o tempo em que ele repousa) segue nos trilhos de uma linha de tempo a qual Benjamin chamaria o progresso, e nossas análises e formas de narrá-lo podem bem descrever o passo dessa locomotiva ou a direção de seu destino, mas pouco fazem para pará-la ou alterar seu rumo. Se assim é, nossa história está aliançada àquela dos que tomam o passado como espólio inócuo e seguem seu cortejo triunfal rumo ao desastre. Mesmo 
críticos, sentamos desconfortavelmente à mesa do banquete dos vencedores, quando poderíamos (e deveríamos) conspirar para descarrilhar esse comboio.

Como construir uma outra relação com o presente, que não o afirme como inexorável na progressão do tempo? Que não sucumba às armadilhas do progresso? Temos ferramentas para tal? Se sim, estamos usando-as?

\section{Outras temporalidades, outras epistemologias}

Se o progresso é a ideologia dos vencedores, como apontou Benjamin no contexto europeu da primeira metade do século XX, e se a história dita oficial é o testamento deixado a seus herdeiros, quem são os beneficiados no nosso contexto espacial e temporal? Quem são os perdedores, reiteradamente obliterados pela tempestade amnésica que nos empurra em direção ao futuro? Como essa dinâmica se reflete e pode ser subvertida na produção de conhecimento e, especificamente, no campo da psicologia social?

De início, para dar materialidade às proposições de Benjamin, poderíamos dizer que a ideia de progresso é racista e colonial na sua própria formulação. Basta lembrar que Hegel - cujas teorias da dialética, da história e do reconhecimento fundamentam em grande parte a concepção de progresso criticada por Benjamin dizia que a África estava desde o princípio fora da história. Fora da razão, portanto, fora do tempo. A esse respeito, Susan Buck-morss (2000) lembra que, embora o espírito de liberdade evocado pela revolução francesa tivesse ocupado um papel importantíssimo como influência para a escrita d'A Fenomenologia do Espírito, a revolução haitiana, que se levantava justamente contra os franceses, e da qual Hegel muito provavelmente tinha conhecimento, é completamente ignorada pelo filósofo. O espírito de liberdade e igualdade evocado pelo iluminismo europeu parece, desde o início, valer apenas para alguns e constituir quem é esse que vale. É nesse sentido que Fanon, já em 1952, e os afropessimistas (Wilderson, 2020; Sexton, 2008), mais recentemente, sublinham que está em jogo na dialética entre senhor e escravo, antes da luta por reconhecimento, a própria delimitação da categoria do humano, a própria delimitação sobre quem tem direito de lutar, da qual estão excluídos, desde sua formulação, negros e negras. A universalidade do progresso e racionalidade, os pilares da modernidade ocidental, são construídos a 
partir da constituição de um campo nãohumano associado à negritude

$\mathrm{O}$ crescimento - em volume e reconhecimento - das discussões relacionadas à raça e gênero que assistimos no ambiente acadêmico brasileiro atualiza, em verdade, uma série de discussões já "antigas" dirigidas a essa pretensa universalidade da razão e do progresso. A partir dos anos oitenta, sob influência da energia mobilizada pelos chamados novos movimentos sociais, materializa-se nas ciências humanas um conjunto de campos de estudo que buscam colocar em xeque esse saber produzido no norte global, majoritariamente por homens brancos, cisgêneros e heterossexuais. Vejamos, então, alguns dos desafios colocados por esses campos e de que maneira enxergamos sua potência para desestabilizar o paradigma ético-estético e seus pressupostos pós-estruturalistas.

Os estudos descoloniais apresentam a discussão acerca da colonialidade do saber. Definidos como um fenômeno histórico complexo, vão se caracterizar a partir dos jogos de poder que operam por meio da "naturalização de hierarquias territoriais, raciais, culturais e epistêmicas, possibilitando a reprodução de relações de dominação" (Restrepo \& Rojas, 2010, p.15 tradução nossa). Nesse sentido, diferem do colonialismo, no que diz respeito ao aparato político-militar desenvolvido para garantir a exploração do trabalho e da riqueza da colônia em prol das metrópoles. Em relação à questão epistemológica, a crítica descolonial está para além da problematização da colonialidade do saber no âmbito acadêmico, se propõe enquanto uma ética e uma política da pluridiversidade, uma igualdade na diferença.

Outra noção importante para pensarmos a relação entre produção de conhecimento e colonialidade do saber é a ideia de epistemicídio. Conceituado por Santos (1997), é apresentado como um instrumento de dominação étnico/racial fundamentado na afirmação de um caminho unidirecional do saber formal. O autor apresenta o epistemicídio ao lado do genocídio, como os dois elementos fundamentais para $\mathrm{o}$ processo $\mathrm{de}$ colonização e produção de um lugar subalternizado e marginalizado de determinados grupos sociais. Carneiro afirma que o epistemicídio é, “para além da anulação e desqualificação do conhecimento dos povos subjugados, um processo persistente de produção da indigência cultural" (2005, p.97).

De maneira análoga, teóricas feministas apontam a naturalização de uma 
perspectiva masculina no pressuposto universal da razão e do conhecimento científico. Isso não significa que a ciência como um todo seja desqualificada. Donna Haraway (1995), por exemplo, sugere que o problema não é a objetividade científica, mas suas pretensões transcendentais e totalizantes. Uma ciência feminista deveria destacar o caráter corporificado do saber, sua relação intrínseca à experiência e, portanto, sua condição parcial e localizada: “A moral é simples: apenas a perspectiva parcial promete visão objetiva" (p. 21). Ao contrário do princípio positivista, que impele ao apagamento dos rastros do pesquisador, à eliminação da subjetividade na construção do conhecimento, e diferente de uma certa leitura do pós-estruturalismo, que flerta perigosamente com os mesmos princípios ao rejeitar qualquer discussão sobre autoria, identidade e experiência, Haraway afirma que é preciso se posicionar. Ou melhor, é preciso levar em consideração o posicionamento das pesquisadoras e pesquisadores nas complexas redes de dominação e regulação social para pensarmos as próprias condições de uma objetividade. "Posicionar-se implica em responsabilidade por nossas práticas capacitadoras. Em consequência, a política e a ética são a base das lutas pela contestação a respeito do que pode ter vigência como conhecimento racional" ( $p$. 27).

Uma das possíveis ferramentas para auxiliar nesse posicionamento é a interseccionalidade, conceito gestado no feminismo negro desde o século XIX, mas nomeado desta forma apenas em 1990, por Kimberlé Crenshaw. Sinteticamente, a interseccionalidade funciona tanto como princípio ético e epistemológico para pesquisas, quanto como diretriz para a ação política, de acordo com o qual devese considerar a interação e a sobreposição de diversos marcadores sociais e estruturas sociais de opressão para compreendermos e analisarmos a desigualdade social de maneira complexa (Collins \& Bulge, 2016). Embora tenha surgido como uma ferramenta relacionada especificamente à análise das vivências de mulheres negras, a interseccionalidade não se atenta especificamente às identidades dos sujeitos, mas à articulação entre diferentes marcadores da diferença, sistemas de opressão e hierarquias sociais (Brah, 2006).

Outra crítica aos pressupostos da neutralidade é tecida por Gayatri Spivak diretamente à Deleuze e Foucault em Pode o subalterno falar? (2010), considerado um dos textos mais importantes do 
pensamento pós-colonial. Como vimos, nas tentativas desses filósofos de desafiar o sujeito cartesiano, encontramos um deslocamento do pensamento desde uma base antropomórfica do indivíduo para uma compreensão baseada em fluxos, práticas, agenciamentos, prazeres, intensidades, regimes de visibilidade e poderes difusos; ou, em outras palavras, um deslocamento desde a identidade à diferença e aos processos de diferenciação. Para Spivak, contudo, essa concepção sobre a diferença é demasiadamente romântica. Em termos como devir-mulher, devir-negro e devir-bicha (a autora não usa exatamente esses exemplos, mas podemos inferi-los), onde Deleuze enxerga uma fonte inesgotável de transformação social, Spivak vê uma dificuldade em considerar as implicações materiais e geográficas dos sistemas de dominação ideológica. Quem, afinal, tem direito a ser esse sujeito flutuante e pós-identitário? Quem pode desfazer-se tão prontamente das marcações de gênero, raça e sexualidade? Ao fazer esses questionamentos, Spivak indica que também há no otimismo da pós-identidade uma homogeneização universalizante que perde de vista a precariedade das populações subalternizadas, especialmente das mulheres do terceiro mundo. $\mathrm{O}$ foco na microfísica do poder ofuscaria uma Rev. Polis e Psique, 2021; 11(1): 123 - 142 compreensão mais ampla do funcionamento macroestrutural do colonialismo e do gênero, sendo a própria filosofia de Foucault e Deleuze sobre a alteridade mais um reflexo da sua condição de homens europeus do que efetivamente um questionamento dessas condições.

Podemos dizer, assim, que tanto o pós-estruturalismo foucaultiano e a filosofia da diferença de Deleuze e Guattari (influências seminais do paradigma ético-estético-político), quanto os estudos descoloniais, feministas, interseccional e pós-colonial, apontam e criticam o conceito de sujeito embutido na pretensa neutralidade da racionalidade positivista. A maneira como o fazem, no entanto, é consideravelmente diferente. Se os primeiros retiram o sujeito da análise ou pelo menos o situam como efeito, mais do que como ponto de partida do conhecimento e da política - os segundos sugerem "destacar" o sujeito, mesmo que compartam a ideia de que esse sujeito é instável. Os estudos de gênero, raça e sobre o colonialismo questionam tanto a pretensão universalista dos saberes disciplinares modernos quanto algumas leituras pós-identitárias que passam a desconfiar da categoria de sujeito na ciência e na filosofia justamente quando grupos minoritários passaram a reivindicá- 
la. Nesse sentido, a retirada do sujeito dos empreendimentos científicos e acadêmicos ameaçaria, em verdade, recolocar subrepticiamente o já conhecido Sujeito homem, branco, europeu, proprietário, citadino, cisgênero e heterossexual - no centro dos intentos filosóficos ocidentais.

Vale notar que as críticas tecidas por essas diferentes perspectivas epistemológicas têm em comum uma importante implicação do ponto de vista da temporalidade. Encontramos na crítica ao projeto da modernidade dos movimentos feminista e antirracista um alinhamento a uma crítica do progresso. Em primeiro lugar, é claro, porque o racismo e o sexismo se estabeleceram e se justificaram/justificam na narrativa de progresso característica dos mitos fundacionais dos estados modernos. Em segundo lugar, porque a ideia de progresso muitas vezes é acionada por argumentos que indicam que de alguma forma já superamos ou que estamos em vias de superar essa problemática - a ideia da democracia racial como superação do racismo, por exemplo -, ou mesmo que essas são questões a serem superadas individualmente, o que contribui para a invisibilização de seu funcionamento insidioso e estrutural.
Ora, uma armadilha se apresenta pelo próprio ferramental terminológico que utilizamos para nomear nosso aliançamento epistemológico. A noção de paradigma é tributária de certa concepção progressista do pensamento. $\mathrm{O}$ entendimento do termo, sobretudo nos círculos acadêmicos, carrega forte herança da elaboração feita por Thomas Kuhn (2017) em A estrutura das revoluções científicas: arcabouço de conceitos, procedimentos e modos de apreender fenômenos que modula (permitindo, mas também limitando) construções teóricas, até que caduque pela sua insuficiência e seja ultrapassado, na acolhida de um novo paradigma (mais permissivo ou robusto). Tal concepção, ainda que não seja de todo problemática, guarda em si o pressuposto de linearidade da história e progresso natural, e impele o pensamento a ideia de superação de determinadas questões quando do alcance de uma maquinaria teórico-conceitual mais refinada.

Se algo aprendemos com a mirada ético-estético-política é que a produção de questões é incessante, mas também que antigos impasses não permanecem em um passado inerte. A insistência de algo que "deveria já ter sido superado" atenta para os elementos que constituem nosso presente enquanto coexistência de tempos 
e problemas, e nos chama a novos posicionamentos e análises para a construção de outros presentes. Tais "falsas superações" devem ser atentadas, mesmo e sobretudo, quando apresentam-se nas próprias construções provenientes desse "paradigma". Os posicionamentos antirracista, anti-colonial e feministas, que convidamos neste debate, diagnosticam uma negligência frente nossas produções e permitem uma revitalização da mirada. Revitalização que o próprio "paradigma" pede incessantemente, enquanto proposta de operar pensamento diferenciante.

\section{Conclusão: radicalização da psicologia social}

Teria o paradigma ético-estéticopolítico entrado em colapso? Seria o assombro diante de questões que julgávamos superadas - o retorno do autoritarismo na política brasileira, e o retorno das questões ditas "identitárias" - o prenúncio do fim de um modo específico de pensar a psicologia social?

Gostaríamos de sugerir outra direção. Diante do colapso epistemológico da psicologia social, processo que coloca em xeque os baluartes teóricos europeus, principalmente no que diz respeito ao caráter localizado da sua produção, Rev. Polis e Psique, 2021; 11(1): 123 - 142 apostamos em uma radicalização da psicologia social. Mas por radicalização não queremos dizer um retorno às “origens", pois isso nada mais faria do que reinserir uma ideia de evolução temporal; antes, nos parece que um movimento de radicalização seria justamente romper com a ideia de progresso que permeia o modo como aprendemos a pensar e fazer psicologia social e que nos parece condensada sobretudo na ideia de paradigma. Radicalizar implica assumir que a mesma modernidade que alicerça a crítica enquanto instrumento de práticas éticas é corolária da hierarquização de saberes e da violência epistemológica. Em outras palavras, radicalizar implica habitar o colapso desse modo de fazer psicologia social, olhar para as suas bases teóricas, fundamentadas em um posicionamento crítico e tornar a própria construção epistemológica alvo dessa crítica, apostar no descarrilamento como metodologia.

No lugar de um paradigma éticoestético-político, parece-nos mais interessante sustentarmos um paradoxo ético-estético-político. Se um paradigma denota um corpo mais ou menos organizado com lugar definido numa história do progresso de um pensamento, o paradoxo aceita o conflito de coexistência entre diversas doxas. Se a lógica 
paradigmática hierarquiza os conhecimentos por suposta sofisticação e evolução num tempo progressivo, o pensamento paradoxal desconfia das superações no tempo e aposta na composição com histórias múltiplas. O presente complexo que nos assalta exige não as resoluções (até arrogantes) possibilitadas pelo paradigma, mas a complexidade de se manter com o problema e construir com ele. Um paradoxo não se resolve, se habita.

Habitar se mostra também um desafio para aqueles que propõem se despir das proteções que a encarnação do paradigma possibilita. A hierarquização paradigmática marca lugares e serve de senha que confere privilégios nesses lugares, e falamos aqui enquanto corpos que nunca tiveram seus lugares na academia questionados. Nós somos aqueles que já estavam aqui, e seguimos aqui com o privilégio de quem não precisou se adequar ou aprender o jargão uma vez comprado. Despir-se do paradigma tem de ser também um exercício de abrir mão da primogenitura epistemológica, para compor com outras histórias e pensamentos em um exercício conflituoso, diplomático e inseguro.

Radicalidade ético-estético-política na psicologia social, então, não como retorno às origens, às raízes do pensamento, posto que é rizoma, mas como apropriação localizada, habitada por outras vozes. Não erigir mestres; povoar e multiplicar. Seguindo as pistas de Neves (2008) a respeito do conhecimento, na perspectiva de uma mirada ético-estética, "conhecer é inventar um campo de problematização a partir de uma desnaturalização (...) e de uma recriação permanente do campo investigado". Recriar permanentemente, inclusive, as bases epistemológicas do pensamento.

\section{Referências}

Benjamin, W. (1987). Magia e técnica, arte e politica: ensaios sobre literatura e história da cultura. Editora Brasiliense.

Brah, A. (2006). Diferença, diversidade, diferenciação. Cadernos Pagu, 26, 329-376. https://doi.org/10.1590/s010483332006000100014

Buck-Morss, S. (2000). Hegel and Haiti. CriticalInquiry, 26(4), 821-865. https://doi.org/10.1086/448993

Carneiro, A. S. (2005). A CONSTRUÇÃO DO OUTRO COMO NÃO-SER COMO FUNDAMENTO DO SER. Universidade de São Paulo.

Crenshaw, K. (1990). Mapping the Margins: Intersectionality, Identity Politics, and Violence against Women of Color. Stanford Law Review, 43. 
Foucault, M. (2014). Verdade, Poder e Si mesmo. In Ditos e escritos, volume V: ética, sexualidade, política (3rd ed., pp. 287-293). Forense Universitária.

Haraway, D. (1995). SABERES LOCALIZADOS: a questão da ciência para o feminismo e o privilégio da perspectiva parcial. Cadernos Pagu, 5, 07-41.

Kuhn, T. (2017). A Estrutura das revoluções científicas (13th ed.). Perspectiva.

Restrepo, E., \& Rojas, A. (2010). Inflexión decolonial: fuentes, conceptos $\mathrm{y}$ cuestionamientos. In Inflexión decolonial: fuentes, conceptos $y$ cuestionamientos. Universidad del Cauca.

Rolnik, S. (2000). Esquizoanálise e antropofagia. In É. Alliez (Ed.), Gilles Deleuze: uma vida filosófica. 34.

Santos, B. de S. (1997). Uma concepção multicultural de direitos humanos. Lua Nova: Revista de Cultura e Política, 39 , 105-124.

https://doi.org/10.1590/s010264451997000100007

Sexton, J. (2008). Amalgamation Schemes: Antiblackness and the Critique of Multiracialism. UnivOf Minnesota Press.

Silva, R. N. da. (2008). Ética e paradigmas: desafios da psicologia social contemporânea. In K. S. Plonder et al. (Ed.), Ética E Paradigmas Na Psicologia Social (pp. 39-45). Centro Edelstein de Pesquisas Sociais. https://doi.org/10.7476/978859966285 4
Spivak, G. C. (2010). Pode o subalterno falar?Editora UFMG.

Wilderson, F. (2020). Afropessimism. Liveright.

\section{Notas}

1. Após amplo debate nacional, foram instituídas, em 2004, as Diretrizes Curriculares Nacionais para os Cursos de Graduação em Psicologia do País (Resolução CNE/CES n ${ }^{\circ} 8$, de 7 de maio de 2004). Engajado nesse processo, o curso Psicologia da UFRGS atualizou seu Projeto Político Pedagógico em 2006, o qual, entre outras resoluções, passa a ter uma presença mais paritária dos três departamentos ao longo de todo o curso. Os três Departamentos que compõem o curso buscam representar a diversidade da Psicologia como ciência e profissão, sendo eles: Psicologia do Desenvolvimento e da Personalidade; Psicologia Social e Institucional, e Psicanálise e Psicopatologia.

2. Em face a cumprir os compromissos assumidos de priorizar o modelo universitário público, de forma a contemplar os princípios fundamentais da autonomia universitária e da indissociabilidade entre ensino, pesquisa e extensão, o governo Lula criou novas universidades federais e investiu na construção de novos campi nas já existentes. O Programa de Expansão Fase I realizou concursos públicos para provimento de 7.668 vagas para docentes e 4.717 para técnicos administrativos. A política de incremento de vagas tomou novo formato durante a segunda gestão, com o Ministro Fernando Haddad, através do Programa de Apoio a Planos de Reestruturação e Expansão das Universidades Federais (Reuni), que incrementou o orçamento das unidades de forma a não só ampliar o número de vagas de acessos como a as iniciativas de apoio à permanência dos estudantes. Sobre a política de expansão e financiamento da educação superior no governo Lula (20032010) pode-se ler mais em Carvalho, Cristina Helena Almeida de. (2014). Principais número Expansão e Reuni (MEC): http://portal.mec.gov.br/index.php?option=co 


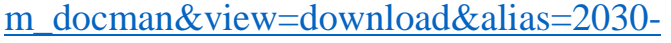

tabela-reuni-271109\&Itemid $=30192$

3. Publicada no Diário Oficial da União em 15

de dezembro de 2016, a Emenda Constitucional 95/2016, institui um novo regime fiscal na Constituição Brasileira, definindo que os gastos federais - excluídos os juros da dívida pública - serão congelados por vinte anos, tendo como base o efetivo gasto em 2016. Conhecida como "PEC da morte" desde sua tramitação na Câmara dos Deputados, essa austeridade econômica diminui o estado, fragiliza toda a rede de proteção social e enfraquece os investimentos em políticas públicas.

4. Em abril de 2019, o então ministro da Educação Abraham Weintraub afirmou que cortaria recursos de universidades que estivessem promovendo "balbúrdia" em seus campi, trazendo como exemplo, eventos e discussões políticas e artísticas, bem como a presença de "sem-terra", em referência aos trabalhadores rurais que reivindicam $\mathrm{O}$ cumprimento da lei de Reforma Agrária. "Universidades que, em vez de procurar melhorar o desempenho acadêmico, estiverem fazendo balbúrdia, terão verbas reduzidas".https://educacao.estadao.com.br/not icias/geral,mec-cortara-verba-de-universidadepor-balburdia-e-ja-mira-unb-uff-eufba, 70002809579

5. Ao longo do texto citaremos as teorias descolonial e pós-colonial. Cabe salientar, contudo, que tais teorias diferem entre si de maneira significativa e faz-se necessário explicitar os principais aspectos de divergência, como nos apontam Restrepo e Rojas (2010). O primeiro aspecto diz respeito à distinção entre colonialidade (problematizada pelos estudos descoloniais) e colonialismo (campo de estudo da teoria pós-colonial), o segundo aspecto diz respeito às experiências históricas, uma vez que os estudos descoloniais remontam à colonização da América Latina e do Caribe (séc XVI a XIX), enquanto os estudo pós-coloniais partem do processo de colonização da Ásia e África (séc XVIII ao $\mathrm{XX)}$ e, como terceiro ponto de diferenciação, os autores marcam que a teoria pós-colonial teria uma gênese epistemológica no pósestruturalismo francês em oposição a uma história do pensamento mais global.
6. Ainda que não tratemos nesse trabalho diretamente de explorar essa afirmação, reconhecemos que a garantia e reserva de vagas (sancionada pela Lei $\mathrm{n}^{\mathrm{o}} 12.711 / 2012$ ) tensiona $\mathrm{o}$ ambiente acadêmico e insere pluralidade de gênero, raça e classe, não só nas carteiras estudantis, mas também nos debates epistêmicos.

7. Escrito por Marx na primavera de 1845 . Publicado pela primeira vez por Engels, em 1888, como apêndice à edição em livro da sua obra Ludwig Feuerbach e o Fim da Filosofia Alemã Clássica, Estugarda 1888, pp. 69-72. Publicado segundo a versão de Engels de 1888, em cotejo com a redação original de Marx. Traduzido do alemão. Disponível em: http://www.dominiopublico.gov.br/download/t exto/ma000081.pdf. Acessado em 18 de agosto de 2019.

8. Entendendo o otimismo enquanto leitura de mundo atrelada a concepção de progresso da história, Benjamin propõe organização do pessimismo como tarefa política que nos cabe. Não só a desconfiança frente ao destino que a história tem formado, mas uma organização estratégica dessa desconfiança que permita ação.

Daniel Kveller é psicólogo, mestre em Psicanálise: Clínica e Cultura (UFRGS) e doutorando pelo Programa de Psicologia Social e Institucional (UFRGS). É membro do Núcleo de Pesquisa em Sexualidade e Relações de Gênero (NUPSEX/UFRGS).

E-mail: dkveller@gmail.com

ORCID:https://orcid.org/0000-0001-9158$\underline{0220}$

Daniel Rodrigues Fernandes é psicólogo, mestre em Psicologia Social e Institucional (UFRGS), doutorando pelo Programa de Psicologia Social e Institucional (UFRGS).

E-mail: drf.daniel@gmail.com

ORCID: http://orcid.org/0000-0002-1963413X

Diego Drescher de Castro é psicólogo, mestre em Psicologia Social e Institucional (UFRGS), doutorando pelo Programa de 
Psicologia Social e Institucional (UFRGS). Membro do Núcleo de Estudos em Imagem, Trabalho e Subjetividade (NEITS/UFRGS).

E-mail: diegodrescher89@gmail.com ORCID:https://orcid.org/0000-0003-2442$\underline{8696}$

Renata Flores Trepte é psicóloga, mestra em Saúde Coletiva (UFRGS) e doutoranda pelo Programa de Psicologia Social e Institucional (UFRGS).

E-mail: renata.trepte@gmail.com

ORCID:https://orcid.org/0000-0001-6750$\underline{7736}$

Submissão: $28 / 09 / 2020$

Aceite: $20 / 11 / 2020$ 